\title{
Improving systems of care during and after a pregnancy complicated by hyperglycaemia: A protocol for a complex health systems intervention
}

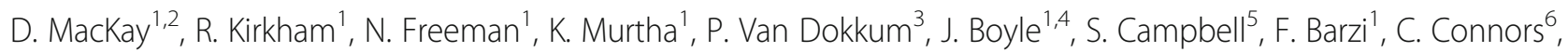
K. O'Dea ${ }^{7,8}$, J. Oats ${ }^{8}$, P. Zimmet ${ }^{9}$, M. Wenitong ${ }^{10}$, A. Sinha ${ }^{11}$, A. J. Hanley ${ }^{12}$, E. Moore ${ }^{13}$, D. Peiris ${ }^{14}$, A. McLean ${ }^{1,11}$,

B. Davis ${ }^{11}$, C. Whitbread ${ }^{1,2}$, H. D. McIntyre ${ }^{15}$, J. Mein ${ }^{16}$, R. McDermott ${ }^{17}$, S. Corpus ${ }^{18}$, K. Canuto ${ }^{19}$, J. E. Shaw ${ }^{20,}$

A. Brown ${ }^{19,21}$, L. Maple-Brown ${ }^{1,2^{*}}$ and on behalf of the Diabetes Across the Lifecourse: Northern Australia Partnership

\section{Abstract}

Background: Many women with hyperglycaemia in pregnancy do not receive care during and after pregnancy according to standards recommended in international guidelines. The burden of hyperglycaemia in pregnancy falls disproportionately upon Indigenous peoples worldwide, including Aboriginal and Torres Strait Islander women in Australia. The remote and regional Australian context poses additional barriers to delivering healthcare, including high staff turnover and a socially disadvantaged population with a high prevalence of diabetes.

\footnotetext{
* Correspondence: louise.maple-brown@menzies.edu.au

'Menzies School of Health Research, Charles Darwin University, Darwin,

Australia

${ }^{2}$ Royal Darwin Hospital, Darwin, Australia

Full list of author information is available at the end of the article
}

(c) The Author(s). 2020 Open Access This article is licensed under a Creative Commons Attribution 4.0 International License, which permits use, sharing, adaptation, distribution and reproduction in any medium or format, as long as you give appropriate credit to the original author(s) and the source, provide a link to the Creative Commons licence, and indicate if changes were made. The images or other third party material in this article are included in the article's Creative Commons licence, unless indicated otherwise in a credit line to the material. If material is not included in the article's Creative Commons licence and your intended use is not permitted by statutory regulation or exceeds the permitted use, you will need to obtain permission directly from the copyright holder. To view a copy of this licence, visit http://creativecommons.org/licenses/by/4.0/. The Creative Commons Public Domain Dedication waiver (http://creativecommons.org/publicdomain/zero/1.0/) applies to the data made available in this article, unless otherwise stated in a credit line to the data. 
(Continued from previous page)

Methods: A complex health systems intervention to improve care for women during and after a pregnancy complicated by hyperglycaemia will be implemented in remote and regional Australia (the Northern Territory and Far North Queensland). The Theoretical Domains Framework was used during formative work with stakeholders to identify intervention components: (1) increasing workforce capacity, skills and knowledge and improving health literacy of health professionals and women; (2) improving access to healthcare through culturally and clinically appropriate pathways; (3) improving information management and communication; (4) enhancing policies and guidelines; (5) embedding use of a clinical register as a quality improvement tool. The intervention will be evaluated utilising the REAIM framework at two timepoints: firstly, a qualitative interim evaluation involving interviews with stakeholders (health professionals, champions and project implementers); and subsequently a mixed-methods final evaluation of outcomes and processes: interviews with stakeholders; survey of health professionals; an audit of electronic health records and clinical register; and a review of operational documents. Outcome measures include changes between pre- and postintervention in: proportion of high risk women receiving recommended glucose screening in early pregnancy; diabetes-related birth outcomes; proportion of women receiving recommended postpartum care including glucose testing; health practitioner confidence in providing care, knowledge and use of relevant guidelines and referral pathways, and perception of care coordination and communication systems; changes to health systems including referral pathways and clinical guidelines.

Discussion: This study will provide insights into the impact of health systems changes in improving care for women with hyperglycaemia during and after pregnancy in a challenging setting. It will also provide detailed information on process measures in the implementation of such health system changes.

Keywords: diabetes in pregnancy, gestational diabetes, type 2 diabetes in pregnancy, health systems, healthcare delivery, health services, mixed methods evaluation, Indigenous Australian, Aboriginal, Torres Strait Islander

\section{Background}

Hyperglycaemia in pregnancy, encompassing gestational diabetes mellitus (GDM), pre-existing type 2 diabetes (T2DM) and overt (likely type 2) diabetes in pregnancy, is associated with adverse health outcomes for mother and child, both in the peripartum period and long-term $[1,2]$. The International Federation of Gynecology and Obstetrics (FIGO) recently identified improving systems of care for women with hyperglycaemia in pregnancy, particularly during the postpartum period, as a research priority [3]. The period during and after pregnancy is an opportune time to optimise maternal health, which is in turn an important strategy to reduce the risk of adverse outcomes in any future pregnancy. International guidelines provide recommendations for the care of women with hyperglycaemia in pregnancy, including postpartum glucose screening and counselling regarding contraception $[4,5]$. However, there are significant gaps in implementing care which meets these recommendations, with a staggering $75-80 \%$ of women lost to follow-up [3], and an average of only $33 \%$ of women internationally completing postpartum glucose testing following GDM [6].

An estimated $16.9 \%$, or 21.4 million, live births around the world are complicated by hyperglycaemia each year [7]. This burden falls disproportionately upon Indigenous women globally [8, 9]. In Australia, Aboriginal and Torres Strait Islander women are 10 times more likely to have pre-existing T2DM in pregnancy, and 1.5 times more likely to develop GDM [10, 11]. GDM is a strong predictor of future T2DM [12]; the risk of progressing to T2DM following GDM is fourfold greater for Aboriginal and Torres Strait Islander women than non-Indigenous women in Australia [13]. Children exposed to hyperglycaemia in utero are at risk of developing T2DM at an early age, which is an issue of increasing concern for the health of Aboriginal and Torres Strait Islander Australians [14, 15]. The consequences of hyperglycaemia in pregnancy contribute substantially to the epidemic of diabetes, and thus to the 10-year gap in life expectancy between Aboriginal and Torres Strait Islander peoples and non-Indigenous Australians [16, 17]. To address disparities in health outcomes between Aboriginal and Torres Strait Islander and non-Indigenous Australians, there is an urgent need to reduce risk as early as possible in the life course.

Prior interventions to improve care for women with hyperglycaemia in pregnancy have predominantly focussed on increasing the proportion of women attending glucose screening after GDM. Single component interventions, such as patient education programs, postpartum reminder systems or use of checklists, have not consistently demonstrated improvements [18-21]. This contrasts with multi-component interventions, which have achieved postpartum glucose screening rates as high as $95.8 \%$ [22-25]. Measures utilised in multicomponent interventions include instituting protocol- 
based care, reminder systems, introduction of a nurse navigator, and education for healthcare providers and women. The impact of such intervention components is yet to be demonstrated in the regional and remote Australian context, where there are multiple barriers to implementing guideline-based recommendations for the care of women with hyperglycaemia in pregnancy. These barriers include a disproportionate burden of socioeconomic disadvantage, population mobility, geographic remoteness, high turnover of clinical staff, and fragmentation between service providers [26].

The Northern Territory Diabetes in Pregnancy (DIP) Partnership formed in 2011 between health service providers, policymakers and researchers to improve the care of women with hyperglycaemia in pregnancy. The Partnership expanded in 2016 to include the region of Far North Queensland, and more recently to consider the intergenerational impact of diabetes, and thus is now the "Diabetes Across the Lifecourse: Northern Australia Partnership" ("the Partnership"). Previous work of the Partnership has included improvements in antenatal service delivery for women with hyperglycaemia in pregnancy in the Northern Territory [26] and the establishment of the DIP Clinical Register [27].

Building on this previous work we have developed a multi-component health systems intervention to improve care for women across regions of northern Australia during and after a pregnancy complicated by hyperglycaemia. Components, which include reminder systems and health practitioner education, have been selected based on evidence for improving care of women with hyperglycaemia in pregnancy in other contexts [23, 25]. An additional component of our intervention is use of the DIP Clinical Register as a recall and continuous quality improvement tool. Clinical registers have been widely utilised, including in regional and remote Australia, to improve systems of care, clinical follow-up and health outcomes for chronic conditions [28, 29]. The Partnership has undertaken formative research with health professionals and stakeholders to identify gaps in care, which contributed to further refining our intervention design $[26,30,31]$.

This protocol describes the planned implementation of our health systems intervention, in accordance with the Template for Intervention Description and Replication (TIDieR) [32] and the Revised Standards for QUality Improvement Reporting Excellence (SQUIRE 2.0) (Supplementary Materials) [33]. These frameworks both provide guidance intending to improve the completeness of reporting, and thus replicability, of healthcare interventions, with SQUIRE 2.0 specifically focussing on health service improvement.

\section{Methods \\ Aim}

To develop, implement and evaluate a health systems intervention to improve models of antenatal and postpartum care for women with hyperglycaemia in pregnancy in regional and remote Australia.

\section{Design}

This study will use a cross-sectional before-and-after design to assess the impacts of the health systems intervention.

\section{Theoretical Framework}

Formative work was conducted with health professionals using the Theoretical Domains Framework (TDF) [34], identifying barriers to the implementation of care according to local guidelines $[35,36]$ for women during and after a pregnancy complicated by diabetes in remote and regional Australia. The TDF describes 12 domains covering the main factors that influence health practitioner clinical behaviour and behaviour changes: knowledge; skills; social/professional role and identity; beliefs about capabilities; beliefs about consequences; motivation and goals; memory, attention and decision processes; environmental context and resources; social influences; emotion; behavioural regulation; and nature of the behaviours. Use of these domains enables identification of a wide range of potential barriers to implementation of improvements in health systems, facilitating development of multiple potential intervention components to overcome the barriers identified.

Detailed barriers and enablers identified by this formative work have been previously reported [31, 37]. In brief, multiple factors impacting on health service delivery were identified, including fragmentation of care, gaps in communication and a lack of clarity regarding healthcare provider responsibilities for components of care such as screening and post-partum follow-up [37]. Further details regarding major barriers are described in Table 1. Opportunities to improve care were also identified, including enhancing education and support for health professionals and improving communication pathways [37].

\section{Setting}

The Northern Territory (NT) and Far North Queensland (FNQ) encompass a geographic area of over 1.6 million square kilometres, including numerous remote islands. The region is sparsely populated, with approximately 500,000 inhabitants [38-40]. Approximately $22.5 \%$ of the population identifies as Aboriginal and/or Torres Strait Islander peoples, compared with $3.2 \%$ across Australia [38-41]. There is a high degree of cultural diversity, with over 200 languages spoken [40]. There are 
Table 1 Barriers to implementing healthcare according to local guidelines for women during and after a pregnancy complicated by diabetes in regional and remote Australia, identified in formative work with healthcare professionals and stakeholders

\begin{tabular}{ll}
\hline System factors & Lack of clarity around roles of healthcare providers in administering diabetes screening tests and providing \\
& follow-up care in the postpartum period \\
& Insufficient involvement of medical specialists \\
& Disjointed communication pathways between hospital and primary care \\
& Inconsistent access to electronic health records \\
& Reliance on handheld medical record, which women may not bring to appointments \\
& Siloed approaches to provision of care \\
& High staff turnover \\
& Small Aboriginal health workforce \\
& Lack of systematic processes for referrals \\
& Unavailability of transport for women to attend for postpartum care \\
& Reported low numbers of women presenting for preconception counselling \\
& Requirement for many women to travel large distances to access care, with reluctance to leave other children \\
& behind \\
& Long waiting times at hospital clinics \\
& Inconsistency in use of local guidelines \\
& Low health practitioner confidence in delivering care \\
Lack of consistency of practitioner knowledge regarding criteria for screening for hyperglycaemia in early \\
pregnancy \\
Healthcare practitioner factors \\
Prioritising needs of family over women's own postpartum health \\
Low perceived future risk of T2DM amongst women \\
Limited time or motivation for women to attend for postpartum care \\
Patient factors
\end{tabular}

approximately 7000 births across the region annually $[11,38,39]$. In the NT in $2015,11.9 \%$ of births to all women were complicated by GDM and $1.7 \%$ by preexisting diabetes; for Aboriginal women, these rates were $15.4 \%$ and $4.1 \%$ respectively [11]. While the official numbers of births affected by diabetes in FNQ are not publicly reported, an audit of births to Aboriginal and Torres Strait Islander women showed the prevalence of GDM and T2DM to be $14.2 \%$ and $2.3 \%$ respectively [42].

This health systems intervention will be conducted across tertiary, secondary and primary healthcare centres, including government and Aboriginal communitycontrolled organisations, throughout three study regions (Central Australia and Top End, within the NT; and FNQ) (Figure 1).

\section{Participants}

Health professionals across the NT and FNQ who are involved in the care or care coordination of women with hyperglycaemia in pregnancy.

\section{Procedures}

Formative focus groups conducted with health professionals in 2016-17 led to the identification of five key models of care components:

1. Increasing workforce capacity, skills and knowledge and improving the health literacy of health professionals and women.

2. Improving access to healthcare through culturally and clinically appropriate pathways.

3. Improving information management and communication.
4. Enhancing policies and guidelines.

5. Embedding the NT and FNQ Diabetes in Pregnancy Clinical Register [27] within the models of care as a continuous quality improvement tool.

\section{Implementation Activities}

The above components have guided the development of implementation activities with local healthcare professionals and stakeholders to address identified barriers (Table 2; Figure 2). A project coordinator will lead implementation of these activities in each study region, with support from the central project office. Activities will be implemented across primary, secondary and tertiary level services throughout each study region, aiming to reach all health services across the regions providing care to women with hyperglycaemia in pregnancy. Due to differences in health systems between the study regions, it is anticipated that there will be context-specific variations in implementation activities across regions. Delivery of activities will be recorded by implementation staff in an Activity Log, including nature of activity, study region, Models of Care component addressed, number of attendees (where relevant), involvement of other organisations and feedback.

Activities and associated materials will be modified throughout the delivery of the project based on feedback from health professionals, project implementers and other stakeholders. The interim evaluation (see below) will provide the main opportunity for feedback and modifications; additional opportunities will be facilitated through regular meetings with stakeholder groups, including a Clinical Reference Group and Indigenous 


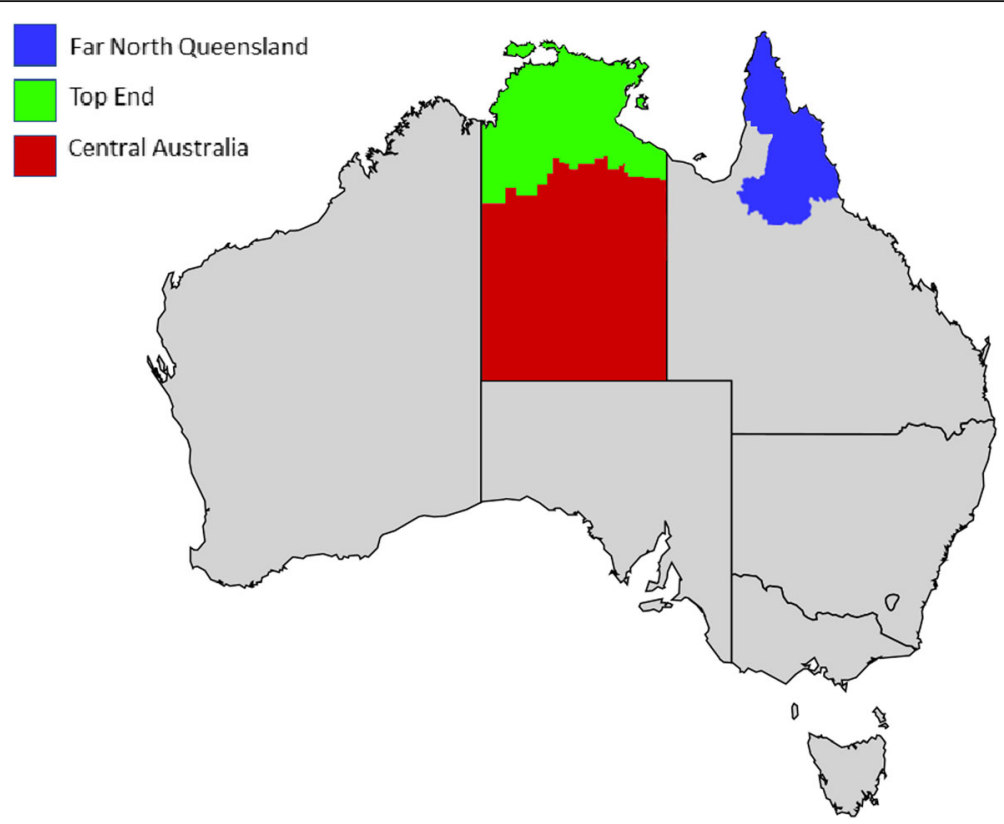

Fig. 1 Study regions for a health systems intervention to improve care for women during and after a pregnancy complicated by diabetes. Adapted from: 'Australia map, States.svg' by Lokal_Profil available at https://commons.wikimedia.org/wiki/File:Australia_map,_States.svg under CC BY-SA 2.5. Full terms at https://creativecommons.org/licenses/by-sa/2.5/deed.en; 'Australian Northern Territory location map.svg' by NordNordWest available at https://commons.wikimedia.org/wiki/File:Australia_Northern_Territory_location_map.svg under CC-BY-SA-3.0-DE. Full terms at https:// creativecommons.org/licenses/by-sa/3.0/de/deed.en; 'Qld region map 2.png' available at https://commons.wikimedia.org/wiki/File:Qld_region_ map_2.PNG under CC BY-SA 3.0. Full terms at https://creativecommons.org/licenses/by-sa/3.0/deed.en

Reference Group in the NT, and a Partnership Working Group in FNQ.

Key implementation activities can be grouped into: educational sessions and resources; recall and reminder systems to assist with follow-up; establishing (in FNQ) and expanding (in NT) the use of the Diabetes in Pregnancy Clinical Register; and stakeholder engagement and consultation (Figure 2). There is substantial overlap between these activities, and many activities align with several of the Models of Care components. Further detail is provided in Table 2 .

Educational Sessions and Resources Implementation staff will collaborate with expert clinicians in the development and delivery of education to health professionals involved in the antenatal and postpartum care of women with hyperglycaemia in pregnancy. Face-to-face and online educational sessions will be designed to reach relevant healthcare providers, with sessions promoted through professional networks and health services. Education will promote evidence-based care according to local guidelines. Educational materials will be made available to interested health professionals for distribution to networks. Key messages will be highlighted in regular newsletters distributed to health professionals and stakeholders (see below, Stakeholder Engagement and Consultation).
Additional educational materials which are culturally appropriate for Aboriginal and Torres Strait Islander women with a pregnancy complicated by diabetes will be developed in collaboration with the Partnership's Indigenous Reference Group and provided to healthcare services for distribution to women.

Recall and Reminder Systems Implementation staff will collaborate with health services to improve systems and enhance recall of women with a pregnancy complicated by diabetes. This will include developing and embedding appropriate postpartum and preconception care plans with reminder systems in primary care electronic health records; improvement of discharge summary templates following hospital discharge; providing postpartum summaries with guideline-based recommendations for ongoing care; and generating postpartum lists from the Diabetes in Pregnancy Clinical Register of women with a recent pregnancy complicated by hyperglycaemia for distribution to primary care services (see below, Diabetes in Pregnancy Clinical Register).

Diabetes in Pregnancy Clinical Register Implementation of the Diabetes in Pregnancy (DIP) Clinical Register in the NT has previously been described in detail [27, 43]. In brief, the register was established in the NT in 2011 and documented all consenting women residing in 
Table 2 Implementation activities to improve care for women during and after a pregnancy complicated by hyperglycaemia

\begin{tabular}{|c|c|c|c|c|c|c|}
\hline Activity & $\begin{array}{l}\text { Models of } \\
\text { Care } \\
\text { Components }\end{array}$ & TDF Domain & Procedure & Materials & Delivered by & Mode of delivery \\
\hline
\end{tabular}

\begin{tabular}{|c|c|c|c|c|c|}
\hline $\begin{array}{l}\text { Education for } \\
\text { healthcare } \\
\text { providers }\end{array}$ & $1,2,3,4$ & $\begin{array}{l}\text { Knowledge; } \\
\text { professional } \\
\text { role; beliefs } \\
\text { about } \\
\text { consequences; } \\
\text { beliefs about } \\
\text { capabilities }\end{array}$ & $\begin{array}{l}\text { Develop an education } \\
\text { calendar across each } \\
\text { region to plan and deliver } \\
\text { educational activities to } \\
\text { healthcare practitioners, } \\
\text { aligning with educational } \\
\text { activities of other regional } \\
\text { healthcare organisations } \\
\text { (e.g. primary care } \\
\text { networks) where possible, } \\
\text { with invitation of } \\
\text { healthcare providers } \\
\text { through healthcare } \\
\text { networks }\end{array}$ & $\begin{array}{l}\text { Presentations, } \\
\text { Newsletters, } \\
\text { Workshops, } \\
\text { Online } \\
\text { resources } \\
\text { (videos, } \\
\text { podcasts) }\end{array}$ & $\begin{array}{l}\text { Educational materials, } \\
\text { including presentation } \\
\text { and text-based materia } \\
\text { will be developed by } \\
\text { ject staff, with input frc } \\
\text { clinical experts (endoc } \\
\text { nologists, diabetes nur } \\
\text { practitioner and educa } \\
\text { tors, primary care prac } \\
\text { tioners) and Indigenou } \\
\text { reference group } \\
\text { Education sessions } \\
\text { delivered by clinicians } \\
\text { and project staff }\end{array}$ \\
\hline
\end{tabular}

\begin{tabular}{|c|c|c|c|}
\hline $\begin{array}{l}\text { Postpartum } \\
\text { care plans and } \\
\text { reminders }\end{array}$ & $2,3,5$ & $\begin{array}{l}\text { Memory, } \\
\text { attention, } \\
\text { decision- } \\
\text { making }\end{array}$ & $\begin{array}{l}\text { Develop postpartum care } \\
\text { plans and reminders to } \\
\text { align with and bridge to } \\
\text { existing Chronic Disease } \\
\text { Care Plan after pregnancy } \\
\text { and embed within } \\
\text { primary healthcare } \\
\text { electronic health record, } \\
\text { to prompt healthcare } \\
\text { provider recall of women } \\
\text { at recommended } \\
\text { timepoints for review } \\
\text { based on guidelines }\end{array}$ \\
\hline $\begin{array}{l}\text { Preconception } \\
\text { care plans }\end{array}$ & $2,3,5$ & $\begin{array}{l}\text { Memory, } \\
\text { attention, } \\
\text { decision- } \\
\text { making }\end{array}$ & $\begin{array}{l}\text { Develop pre-conception } \\
\text { care plans and embed } \\
\text { within primary healthcare } \\
\text { electronic health record, } \\
\text { to prompt healthcare pro-- } \\
\text { vider to ensure recom- } \\
\text { mended pre-conception } \\
\text { care is delivered to } \\
\text { women with pre-existing } \\
\text { diabetes based on } \\
\text { guidelines }\end{array}$ \\
\hline
\end{tabular}

$\begin{array}{lll}\begin{array}{l}\text { Indigenous } \\ \text { reference } \\ \text { group }\end{array} & 2,3 & \begin{array}{l}\text { Social } \\ \text { influences }\end{array}\end{array}$

Form an Indigenous reference group to provide input regarding
Selected sessions will be recorded and delivered online to enable access for practitioners unable to attend, with information for access distributed and promoted through Partnership networks and health practitioner organisations Newsletters to be distributed to healthcare providers and stakeholders through Partnership networks

Annual symposium, with healthcare providers and other stakeholders invited through Partnership networks

Electronic primary care health record

Implementation team in collaboration with health services staff, with input from clinical reference group

Electronic primary care health record

PhD student with input from clinical reference

Electronic primary care health record

Advice from priority-setting, resource development and implementation, by inviting

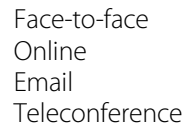


Table 2 Implementation activities to improve care for women during and after a pregnancy complicated by hyperglycaemia (Continued)

\begin{tabular}{|c|c|c|c|c|c|c|c|}
\hline Activity & $\begin{array}{l}\text { Models of } \\
\text { Care } \\
\text { Components }\end{array}$ & TDF Domain & Procedure & Materials & Delivered by & Mode of delivery & $\begin{array}{l}\text { Region } \\
\text { (TE, CA, } \\
\text { FNQ, } \\
\text { All) }\end{array}$ \\
\hline & & & $\begin{array}{l}\text { Indigenous women with } \\
\text { an interest in hypergly- } \\
\text { caemia in pregnancy, } \\
\text { meeting three times per } \\
\text { year and feeding back to } \\
\text { investigators and project } \\
\text { staff }\end{array}$ & $\begin{array}{l}\text { Health } \\
\text { Research }\end{array}$ & & & \\
\hline $\begin{array}{l}\text { Clinical } \\
\text { reference } \\
\text { group }\end{array}$ & 2,3 & $\begin{array}{l}\text { Social } \\
\text { influences; } \\
\text { motivation and } \\
\text { goals }\end{array}$ & $\begin{array}{l}\text { Ongoing facilitation of a } \\
\text { reference group of } \\
\text { clinicians to provide input } \\
\text { regarding priority-setting, } \\
\text { resource development } \\
\text { and implementation, by } \\
\text { inviting interested clini- } \\
\text { cians through Partnership } \\
\text { networks, to meet annu- } \\
\text { ally and feed back to in- } \\
\text { vestigators and project } \\
\text { staff }\end{array}$ & $\begin{array}{l}\text { Presentations; } \\
\text { meetings; } \\
\text { circulation of } \\
\text { documents/ } \\
\text { resources for } \\
\text { comment }\end{array}$ & $\begin{array}{l}\text { Coordinated by } \\
\text { implementation team }\end{array}$ & $\begin{array}{l}\text { Face-to-face, } \\
\text { with clinicians } \\
\text { provided with } \\
\text { email address to } \\
\text { provide feedback } \\
\text { between } \\
\text { meetings }\end{array}$ & $\mathrm{TE}, \mathrm{CA}$ \\
\hline $\begin{array}{l}\text { Working } \\
\text { group }\end{array}$ & 2,3 & $\begin{array}{l}\text { Social } \\
\text { influences; } \\
\text { motivation and } \\
\text { goals }\end{array}$ & $\begin{array}{l}\text { Form a working group } \\
\text { with representatives from } \\
\text { partner organisations to } \\
\text { provide input regarding } \\
\text { priority-setting, resource } \\
\text { development and imple- } \\
\text { mentation, as well as op- } \\
\text { portunity for promotion of } \\
\text { educational opportunities }\end{array}$ & $\begin{array}{l}\text { Presentations; } \\
\text { meetings; } \\
\text { circulation of } \\
\text { documents/ } \\
\text { resources for } \\
\text { comment }\end{array}$ & $\begin{array}{l}\text { Coordinated by } \\
\text { implementation team }\end{array}$ & $\begin{array}{l}\text { Face-to-face } \\
\text { meetings } \\
\text { alternate months }\end{array}$ & FNQ \\
\hline $\begin{array}{l}\text { Resource } \\
\text { development }\end{array}$ & $1,2,3$ & $\begin{array}{l}\text { Environmental } \\
\text { context and } \\
\text { resources }\end{array}$ & $\begin{array}{l}\text { Development of culturally } \\
\text { appropriate resources to } \\
\text { assist healthcare providers } \\
\text { in discussions with } \\
\text { women about health after } \\
\text { a pregnancy complicated } \\
\text { by diabetes }\end{array}$ & $\begin{array}{l}\text { Postpartum } \\
\text { discharge } \\
\text { brochure }\end{array}$ & $\begin{array}{l}\text { Discharge brochure } \\
\text { developed by } \\
\text { implementation team } \\
\text { with input from clinical } \\
\text { experts }\end{array}$ & Paper-based & All \\
\hline $\begin{array}{l}\text { Aggregate DIP } \\
\text { Clinical } \\
\text { Register } \\
\text { reports }\end{array}$ & $1,3,5$ & $\begin{array}{l}\text { Knowledge; } \\
\text { motivation and } \\
\text { goals }\end{array}$ & $\begin{array}{l}\text { Produce de-identified ag- } \\
\text { gregate postpartum re-- } \\
\text { ports from the DIP Clinical } \\
\text { Register six-monthly dis- } \\
\text { tribute to healthcare pro- } \\
\text { viders and stakeholders to } \\
\text { enable quality improve- } \\
\text { ment activities }\end{array}$ & $\begin{array}{l}\text { DIP Clinical } \\
\text { Register }\end{array}$ & Implementation team & Email & All \\
\hline $\begin{array}{l}\text { Local DIP } \\
\text { Clinical } \\
\text { Register } \\
\text { reports }\end{array}$ & $1,3,5$ & $\begin{array}{l}\text { Memory, } \\
\text { attention, } \\
\text { decision- } \\
\text { making }\end{array}$ & $\begin{array}{l}\text { Produce local postpartum } \\
\text { reports with identifiable } \\
\text { data from the DIP Clinical } \\
\text { Register six-monthly and } \\
\text { distribute to healthcare } \\
\text { providers to aid in quality } \\
\text { improvement activities } \\
\text { and recall of women }\end{array}$ & $\begin{array}{l}\text { DIP Clinical } \\
\text { Register }\end{array}$ & Implementation team & Email & $\mathrm{TE}, \mathrm{CA}$ \\
\hline $\begin{array}{l}\text { Modified } \\
\text { discharge } \\
\text { summaries }\end{array}$ & 3,5 & $\begin{array}{l}\text { Memory, } \\
\text { attention, } \\
\text { decision- }\end{array}$ & $\begin{array}{l}\text { Review and amend } \\
\text { current discharge } \\
\text { summary templates for }\end{array}$ & $\begin{array}{l}\text { Discharge } \\
\text { summaries }\end{array}$ & Implementation team & $\begin{array}{l}\text { Within electronic } \\
\text { discharge } \\
\text { summary }\end{array}$ & $\mathrm{TE}, \mathrm{CA}$ \\
\hline
\end{tabular}


Table 2 Implementation activities to improve care for women during and after a pregnancy complicated by hyperglycaemia (Continued)

\begin{tabular}{|c|c|c|c|c|c|c|c|}
\hline Activity & $\begin{array}{l}\text { Models of } \\
\text { Care } \\
\text { Components }\end{array}$ & TDF Domain & Procedure & Materials & Delivered by & Mode of delivery & $\begin{array}{l}\text { Region } \\
\text { (TE, CA, } \\
\text { FNQ, } \\
\text { All) }\end{array}$ \\
\hline $\begin{array}{l}\text { Postpartum } \\
\text { summary }\end{array}$ & 3,5 & $\begin{array}{l}\text { Memory, } \\
\text { attention, } \\
\text { decision- } \\
\text { making }\end{array}$ & $\begin{array}{l}\text { Generate postpartum } \\
\text { diabetes in pregnancy } \\
\text { summary using DIP } \\
\text { Clinical Register data and } \\
\text { distribute to healthcare } \\
\text { providers, including } \\
\text { reminder for postpartum } \\
\text { screening }\end{array}$ & $\begin{array}{l}\text { DIP Clinical } \\
\text { Register }\end{array}$ & Implementation team & Letter & FNQ \\
\hline $\begin{array}{l}\text { Postpartum } \\
\text { screening } \\
\text { reminder } \\
\text { letters }\end{array}$ & 3,5 & $\begin{array}{l}\text { Memory, } \\
\text { attention, } \\
\text { decision- } \\
\text { making }\end{array}$ & $\begin{array}{l}\text { Generate letters to } \\
\text { healthcare providers using } \\
\text { DIP Clinical Register data } \\
\text { to prompt recall of } \\
\text { women for recommended } \\
\text { postpartum glucose check } \\
\text { if check not recorded } \\
\text { within six months } \\
\text { postpartum }\end{array}$ & $\begin{array}{l}\text { DIP Clinical } \\
\text { Register }\end{array}$ & Implementation team & Letter & FNQ \\
\hline $\begin{array}{l}\text { Promotion of } \\
\text { postpartum } \\
\text { guidelines by } \\
\text { champions }\end{array}$ & 1,4 & $\begin{array}{l}\text { Social } \\
\text { influences }\end{array}$ & $\begin{array}{l}\text { Champions identified } \\
\text { through engagement with } \\
\text { Partnership activities, and } \\
\text { upskilled regarding use of } \\
\text { local guidelines through } \\
\text { Partnership educational } \\
\text { activities and publications }\end{array}$ & $\begin{array}{l}\text { Local clinical } \\
\text { guidelines - } \\
\text { CARPA (CA, } \\
\text { TE), QCG } \\
\text { (FNQ) }\end{array}$ & Implementation team & $\begin{array}{l}\text { Face-to-face, } \\
\text { email }\end{array}$ & All \\
\hline
\end{tabular}

Models of Care Components: 1 - Increasing workforce capacity, skills and knowledge and improvement in the health literacy of health professionals and women; 2 - Improving access to culturally and clinically appropriate healthcare; 3 - Improving information management and communication; 4 - Enhancing policy and guidelines; 5 - Embedding the Diabetes in Pregnancy Clinical Register as a component with the Models of Care

Abbreviations: CA Central Australia, CARPA Central Australian Rural Practitioners Association (2017), DIP Diabetes in Pregnancy, FNQ Far North Queensland, QCG Queensland Clinical Guidelines (2015), TDF Theoretical Domain Framework, TE Top End, the Partnership - Diabetes Across the Lifecourse: Northern Australia Partnership

the NT aged 16 years and over with any type of hyperglycaemia in pregnancy, referred by a health professional.

In the current health systems intervention, the implementation team will collaborate with health services to establish the DIP Clinical Register in FNQ, and expand its use in the NT. This will include streamlining referral processes by embedding referrals within electronic health records of health services where possible. Functions of the DIP Clinical Register include producing and distributing local postpartum reports with details of women attending specific primary healthcare services who have recently given birth, to aid with recall of women and quality improvement activities. In addition, de-identified aggregate reports including all women across the NT and FNQ are produced and distributed to healthcare providers and stakeholders as a quality improvement and epidemiological tool. Implementation staff will work with healthcare staff to use findings of aggregated DIP Clinical Register reports as quality improvement tools to inform changes in models of care and improve integration between primary and hospitalbased care.
Stakeholder Engagement and Consultation Ongoing collaboration with stakeholders will be essential for implementation of this health systems intervention. The Partnership has established reference groups (a Clinical Reference Group and an Indigenous Reference Group in the NT, and a Partnership Working Group in FNQ), who will meet regularly throughout the health systems intervention to provide feedback on implementation activities and guide ongoing priorities of the intervention. Additional consultation will occur frequently with key health service representatives and champions. The Partnership will produce regular newsletters to provide educational messages and update health practitioners and stakeholders on project activities.

\section{Evaluation}

This health systems intervention will be evaluated using the five dimensions of the RE-AIM framework: reach (the proportion and representativeness of participants relative to target population), effectiveness (impacts of the program), adoption (uptake of the intervention), implementation (the extent to which the intervention was delivered as intended) and maintenance (the extent to 


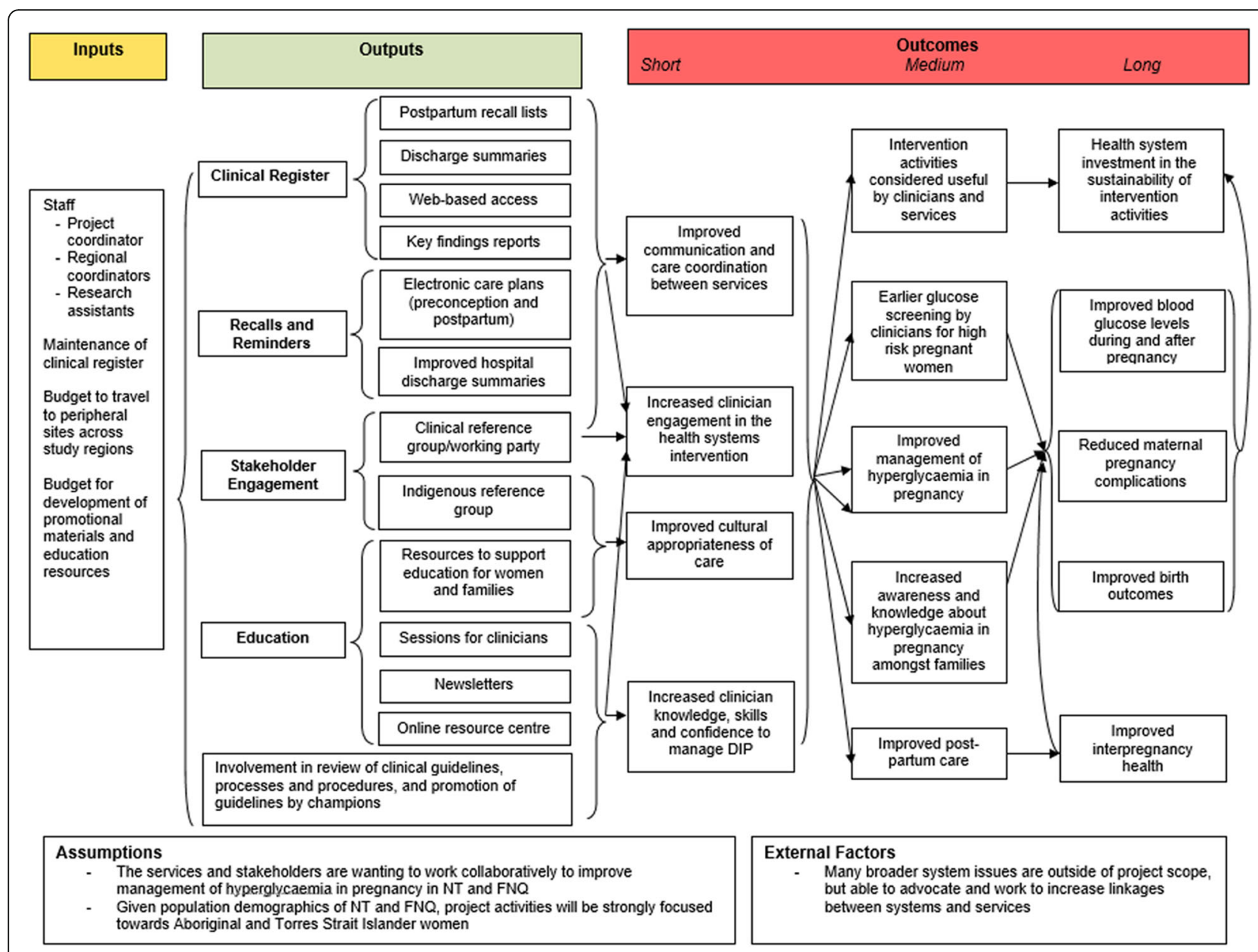

Fig. 2 Logic model for a health systems intervention to improve care for women during and after a pregnancy complicated by diabetes

which the intervention is institutionalised into routine organisational practices and policies) [44-46].

Evaluation indicators for each phase of the evaluation have been developed and structured within the RE-AIM framework (Tables 3 and 4) [44]. Outcome measures include changes between baseline and post-intervention in indicators of care provided to women, including: proportion of high risk women receiving recommended glucose screening in early pregnancy; first and third trimester HbA1c in women with T2DM; and proportion of women receiving recommended postpartum care (glucose testing, breastfeeding, weight management, smoking education and discussion or prescription of contraception). We will also assess changes in health practitioner confidence in providing care, knowledge and use of relevant guidelines and referral pathways, and perception of care coordination and communication systems; and changes to health systems including referral pathways and clinical guidelines.

Changes in birth and neonatal outcomes will be assessed to determine the impact of health system changes, including: gestational age at delivery; mode of delivery; birth weight; large for gestational age; small for gestational age; macrosomia; neonatal obstetric trauma; neonatal hypoglycaemia requiring treatment; neonatal special care admission; 5-minute APGAR score less than 5 ; neonatal jaundice requiring treatment; and neonatal respiratory distress.

The health systems intervention will be evaluated across multiple levels (individual health practitioner, clinic, health system, community), with data collection occurring at three timepoints:

1. Baseline, prior to implementation of the intervention, to enable comparison across indicators pre- and post-intervention.

2. A qualitative interim evaluation, to be conducted at least 12 months after delivery of intervention activities has commenced across all regions, focusing on identifying and exploring barriers and enablers of implementation of and engagement with the health systems intervention. Findings from this 
Table 3 Indicators for the interim evaluation of a health systems intervention to improve care during and after a pregnancy complicated by diabetes

\begin{tabular}{|c|c|c|}
\hline RE-AIM & Indicator & Data Sources \\
\hline $\begin{array}{l}\text { Reach } \\
\text { - levels of participation and characteristics of } \\
\text { participants }\end{array}$ & $\begin{array}{l}\text {-Awareness of the Partnership and associated activities } \\
\text { - Role of participant and level of engagement with hyperglycaemia in } \\
\text { pregnancy clients }\end{array}$ & $\begin{array}{l}\text { Health professionals } \\
\text { Implementation } \\
\text { team, enablers, } \\
\text { champions }\end{array}$ \\
\hline $\begin{array}{l}\text { Effectiveness } \\
\text { - positive and negative consequences of the intervention }\end{array}$ & $\begin{array}{l}\text {-Perceived level of effectiveness of resources/activities for improving } \\
\text { management of hyperglycaemia in pregnancy } \\
\text {-Acknowledgement of factors that contribute to effectiveness/ } \\
\text { explanation of varying levels of effectiveness }\end{array}$ & $\begin{array}{l}\text { Health professionals } \\
\text { Implementation } \\
\text { team, enablers, } \\
\text { champions }\end{array}$ \\
\hline $\begin{array}{l}\text { Adoption } \\
\text { - proportion and representativeness of settings and } \\
\text { providers who have adopted the intervention (or } \\
\text { components of it) }\end{array}$ & $\begin{array}{l}\text {-Knowledge and/or resources have been adopted in practice or } \\
\text { intended to be adopted (i.e. improved management practices } \\
\text { adopted such as - follow-up plans, OGT's, Chronic Disease Manage- } \\
\text { ment Plans) } \\
\text {-Issues related to not taking up Partnership activity opportunities and/ } \\
\text { or not implementing related activities }\end{array}$ & $\begin{array}{l}\text { Health professionals } \\
\text { Implementation } \\
\text { team, enablers, } \\
\text { champions }\end{array}$ \\
\hline $\begin{array}{l}\text { Implementation } \\
\text { - the intervention is delivered as intended }\end{array}$ & $\begin{array}{l}\text {-Extent that the Models of Care components*/implementation } \\
\text { activities are being delivered as planned/expected, by whom and } \\
\text { when } \\
\text {-Adaptations made to original implementation plan }\end{array}$ & $\begin{array}{l}\text { Implementation } \\
\text { team, enablers, } \\
\text { champions }\end{array}$ \\
\hline $\begin{array}{l}\text { Maintenance } \\
\text { - practice or policy becomes routine and part of } \\
\text { everyday culture and norms }\end{array}$ & $\begin{array}{l}\text {-Extent that the Models of Care components*/implementation } \\
\text { activities have been embedded into regular practice } \\
\text {-Intention to continue new practices beyond the project's funding } \\
\text { cycle }\end{array}$ & $\begin{array}{l}\text { Health professionals } \\
\text { Implementation } \\
\text { team, enablers, } \\
\text { champions }\end{array}$ \\
\hline
\end{tabular}

"The Partnership" - the Diabetes Across the Lifecourse: Northern Australia Partnership; OGTT - 75 gram oral glucose tolerance test

*Models of Care Components: 1 - Increasing workforce capacity, skills and knowledge and improvement in the health literacy of health professionals and women; 2 - Improving access to culturally and clinically appropriate healthcare; 3 - Improving information management and communication; 4 - Enhancing policy and guidelines; 5 - Embedding the Diabetes in Pregnancy Clinical Register as a component with the Models of Care

interim evaluation will inform modifications of the intervention, for the remainder of the implementation period.

3. A mixed-methods final evaluation of outcomes and processes of the health systems intervention, after completion of the implementation period. This evaluation will address whether the health systems intervention has improved systems of care for women during and after a pregnancy complicated by diabetes; which implementation activities have contributed to improvements; enablers and barriers impacting on the success of implementation activities; social validity of the health systems intervention (from the perspectives of healthcare providers, champions and stakeholders); and how implementation activities can be sustained beyond completion of the intervention. Quantitative data will include measures of care provided during and after pregnancy, as well as birth outcomes.

\section{Data Collection}

Data will be collected from four sources: interviews with healthcare providers and stakeholders; healthcare provider survey; cross-sectional pre- and post-intervention audits of electronic health records and the Diabetes in Pregnancy Clinical Register; and implementation operational documents. Six primary healthcare services, including one government and one community-controlled service in each of the three study regions, will be evaluation case study sites. Case study sites include both an urban and a remote service in each study region. Data will additionally be collected at the regional health service level, including regional referral hospitals and health service management.

Semi-Structured Interviews Healthcare providers and stakeholders at each of the evaluation case study sites will be interviewed during both the interim and final evaluations. Additional interviews will be conducted with relevant stakeholders at the major referral hospital within each region (Top End: Royal Darwin Hospital; Central Australia: Alice Springs Hospital; FNQ: Cairns Hospital), and with policymakers and managers at the regional health service level, as well as with members of the implementation team. These interviews will be guided by a social constructionist epistemological perspective, utilising a phenomenological approach. Interview topics will include awareness of, engagement with and utility of activities of the health systems intervention, and the impact of intervention activities on practice. Interviews with implementation staff will additionally address process measures including barriers and facilitators to implementing intervention activities, any adaptations to implementation activities and the rationale and success for these adaptations. Interviews during the final evaluation will also explore healthcare provider 
Table 4 Indicators for the final evaluation of a health systems intervention to improve care during and after a pregnancy complicated by diabetes

\begin{tabular}{|c|c|c|c|}
\hline Objective & $\begin{array}{l}\text { Final Indicator } \\
\text { evaluation } \\
\text { question } \\
\text { addressed* }\end{array}$ & Data source & Data collection \\
\hline
\end{tabular}

REACH

Increase (FNQ) and sustain (NT) engagement 3 of clinicians with the project

Improve health practitioner awareness of
DIP Clinical Register
Increase (FNQ) and sustain (NT) coverage of
the DIP Clinical Register

the DIP Clinical Register

Determine the number and characteristics of women accessing and not accessing antenatal care

\section{EFFECTIVENESS}

Enhance support for health practitioners

Increase health practitioner awareness of and confidence in managing hyperglycaemia in pregnancy

Earlier hyperglycaemia in pregnancy screening women at high risk

Improved blood glucose levels for women with diabetes in pregnancy

Improved birth and neonatal outcomes
Improve health practitioners' awareness of postpartum guidelines

Improve postpartum management, according to guidelines, following diabetes in pregnancy
Health practitioner awareness of Partnership and activities

Health practitioner attendance at Partnership education events

Use of project online health professional educational resources

Health practitioner awareness of DIP Clinical Register

DIP Clinical Register coverage; trajectory of coverage over time

Number of women accessing antenatal care, including number and timing of visits

Health practitioner perception of support

Health practitioner and champion reports of which activities have been useful in enhancing support

Health practitioners perceived knowledge and confidence, and changes from Partnership formative work

Rates of completion of recommended glucose screening in early pregnancy for high risk women

Rates of completion of recommended early pregnancy screening for high risk women

Mean first- and third-trimester $\mathrm{HbA} 1 \mathrm{c}$ and changes over time

Gestational age at delivery

Mode of delivery

Birth weight

Large for gestational age

Small for gestational age

Macrosomia

Neonatal obstetric trauma

Neonatal hypoglycaemia requiring

treatment

Neonatal special care admission

5-minute APGAR score less than 5

Neonatal jaundice requiring treatment

Neonatal respiratory distress

Health practitioner awareness of guidelines and changes over time

Proportion of women completing postpartum glucose testing

Postpartum weight, body mass index waist circumference
Health professionals Interviews

Project activity log Surveys

Website

Activity log

Metrics from website

Health professionals Interviews DIP Clinical Register Surveys

Comparison of DIP Health service Clinical Register with reports health service data

Health service

Audit electronic health records

DIP Clinical Register Health service reports ${ }^{1}$

Health professionals

Interviews

Champions

Surveys

Health professionals

Interviews

Health service Surveys

electronic health

records

DIP Clinical Register

Audit

Formative DIP Models of Care work

DIP Clinical Register

Audit

DIP Clinical Register Audit

DIP Clinical Register Audit

Health professionals

Interviews

Champions

surveys

Electronic health Audit records

DIP Clinical Register 
Table 4 Indicators for the final evaluation of a health systems intervention to improve care during and after a pregnancy complicated by diabetes (Continued)

\begin{tabular}{|c|c|c|c|c|}
\hline Objective & $\begin{array}{l}\text { Final } \\
\text { evaluation } \\
\text { question } \\
\text { addressed* }\end{array}$ & Indicator & Data source & Data collection \\
\hline & & $\begin{array}{l}\text { Proportion of women breastfeeding } \\
\text { Proportion of women smoking } \\
\text { Proportion of women prescribed } \\
\text { contraception, or who have discussed } \\
\text { contraception with a health practitioner } \\
\text { Changes over time in all indicators }\end{array}$ & & \\
\hline \multirow[t]{2}{*}{$\begin{array}{l}\text { Enhance communication between primary } \\
\text { healthcare and hospital services }\end{array}$} & 1 & $\begin{array}{l}\text { Health practitioner perception of } \\
\text { communication between primary } \\
\text { healthcare and hospital services }\end{array}$ & Health professionals & Interviews \\
\hline & 3 & $\begin{array}{l}\text { Health practitioner and champion } \\
\text { reports of which activities have } \\
\text { contributed to changes }\end{array}$ & Champions & Surveys \\
\hline \multirow{3}{*}{$\begin{array}{l}\text { Improve referral pathways and care } \\
\text { coordination for services caring for women } \\
\text { with hyperglycaemia in pregnancy }\end{array}$} & 1 & $\begin{array}{l}\text { Health practitioner knowledge of referral } \\
\text { pathways }\end{array}$ & Health professionals & Interviews \\
\hline & 1 & $\begin{array}{l}\text { Health practitioner perception of } \\
\text { improvements in care coordination }\end{array}$ & Champions & Surveys \\
\hline & 3 & $\begin{array}{l}\text { Health practitioner and champion } \\
\text { reports of which activities have } \\
\text { contributed to changes }\end{array}$ & & \\
\hline \multirow[t]{2}{*}{ Improve discharge processes } & 1 & $\begin{array}{l}\text { Health practitioner perception of } \\
\text { usefulness of discharge summaries }\end{array}$ & Health professionals & Interviews \\
\hline & 1 & $\begin{array}{l}\text { Health practitioner and champion } \\
\text { perception of impact of discharge } \\
\text { processes on postpartum care }\end{array}$ & Champions & Surveys \\
\hline \multicolumn{5}{|l|}{ ADOPTION } \\
\hline \multirow[t]{2}{*}{ Enhance referrals to DIP Clinical Register } & 1 & DIP Clinical Register coverage & \multirow{2}{*}{$\begin{array}{l}\text { Comparison of DIP } \\
\text { Clinical Register with } \\
\text { health service data } \\
\text { Health professionals }\end{array}$} & \multirow{2}{*}{$\begin{array}{l}\text { Health service } \\
\text { reports } \\
\text { Interviews }^{1} \\
\text { Surveys }\end{array}$} \\
\hline & 3 & $\begin{array}{l}\text { Health service perceptions of referral } \\
\text { process }\end{array}$ & & \\
\hline \multirow[t]{2}{*}{$\begin{array}{l}\text { Improve practitioner use of DIP Clinical } \\
\text { Register }\end{array}$} & 1 & $\begin{array}{l}\text { Health practitioner use of DIP Clinical } \\
\text { Register and reports }\end{array}$ & Health professionals & Interviews \\
\hline & 3 & $\begin{array}{l}\text { Health practitioner reports of which } \\
\text { aspects of reports are useful in practice }\end{array}$ & DIP Clinical Register & $\begin{array}{l}\text { Surveys } \\
\text { External use of DIP } \\
\text { Clinical Register } \\
\text { website, e.g. website } \\
\text { metrics }\end{array}$ \\
\hline $\begin{array}{l}\text { Identify enablers and barriers impacting on } \\
\text { adoption of project activities }\end{array}$ & 3 & $\begin{array}{l}\text { Health practitioner, implementer and } \\
\text { champion reports of enablers and } \\
\text { barriers }\end{array}$ & $\begin{array}{l}\text { Health professionals } \\
\text { Implementers } \\
\text { Champions }\end{array}$ & Interviews \\
\hline $\begin{array}{l}\text { Determine acceptability and value of project } \\
\text { activities } \\
\text {-Are project activities socially appropriate/ } \\
\text { acceptable? } \\
\text {-What is the social importance of project } \\
\text { outcomes? } \\
\text {-Which project activities are perceived as } \\
\text { valuable? }\end{array}$ & 4 & $\begin{array}{l}\text { Health practitioner, implementer and } \\
\text { champion perceptions of acceptability } \\
\text { and value of project activities }\end{array}$ & $\begin{array}{l}\text { Health professionals } \\
\text { Implementers } \\
\text { Champions } \\
\text { Women }\end{array}$ & Interviews \\
\hline \multicolumn{5}{|l|}{ IMPLEMENTATION } \\
\hline $\begin{array}{l}\text { Determine if project activities have been } \\
\text { delivered as intended }\end{array}$ & 3 & Proportion of planned activities delivered & $\begin{array}{l}\text { Project activity log } \\
\text { Implementers }\end{array}$ & $\begin{array}{l}\text { Interviews } \\
\text { Audit of activity log }\end{array}$ \\
\hline $\begin{array}{l}\text { Determine if project activities have been } \\
\text { adapted, e.g. to fit local needs }\end{array}$ & 3 & $\begin{array}{l}\text { Adaptations of planned activities and } \\
\text { rationale }\end{array}$ & Implementers & Interviews \\
\hline $\begin{array}{l}\text { Identify enablers and barriers impacting on } \\
\text { implementation of project activities }\end{array}$ & 3 & $\begin{array}{l}\text { Enablers and barriers as identified by } \\
\text { implementation team }\end{array}$ & $\begin{array}{l}\text { Implementers } \\
\text { Health professionals } \\
\text { Champions }\end{array}$ & Interviews \\
\hline
\end{tabular}


Table 4 Indicators for the final evaluation of a health systems intervention to improve care during and after a pregnancy complicated by diabetes (Continued)

\begin{tabular}{|c|c|c|c|c|}
\hline Objective & $\begin{array}{l}\text { Final } \\
\text { evaluation } \\
\text { question } \\
\text { addressed* }^{*}\end{array}$ & Indicator & Data source & Data collection \\
\hline \multicolumn{5}{|l|}{ MAINTENANCE } \\
\hline $\begin{array}{l}\text { Sustain DIP Clinical Register through } \\
\text { integration with other structures }\end{array}$ & 5 & $\begin{array}{l}\text { Health practitioners and services } \\
\text { perceptions of sustainability of the DIP } \\
\text { Clinical Register } \\
\text { Resources required and cost of } \\
\text { maintaining DIP Clinical Register }\end{array}$ & $\begin{array}{l}\text { Health professionals } \\
\text { Champions } \\
\text { Implementers } \\
\text { Activity log }\end{array}$ & $\begin{array}{l}\text { Interviews } \\
\text { Surveys } \\
\text { Cost-consequences } \\
\text { analysis }\end{array}$ \\
\hline $\begin{array}{l}\text { Identify project activities sustainable beyond } \\
\text { project completion, and method for funding } \\
\text { or integration into existing services }\end{array}$ & 5 & $\begin{array}{l}\text { Health professional, champion and } \\
\text { implementer perception of sustainability } \\
\text { of project activities } \\
\text { Resources required for project activity } \\
\text { sustainability }\end{array}$ & $\begin{array}{l}\text { Health professionals } \\
\text { Champions } \\
\text { Implementers } \\
\text { Activity log }\end{array}$ & $\begin{array}{l}\text { Interviews } \\
\text { Cost-consequences } \\
\text { analysis }\end{array}$ \\
\hline
\end{tabular}

*Evaluation questions: 1. To what degree has the health systems intervention improved systems of care during and after a pregnancy complicated by hyperglycaemia?; 2. To what degree has the health systems intervention improved maternal and neonatal outcomes during and after a pregnancy complicated by hyperglycaemia?; 3. If improvements are demonstrated, which activities of the health systems intervention have contributed to this improvement, and what enablers and barriers have impacted on the success of these activities?; 4. Are activities considered socially valid by healthcare providers, champions and stakeholders?; 5. How do the resources required for project activities balance against the benefits?; 6 . How can the Partnership support the continuation of successful project activities after completion of the health systems intervention? Abbreviations: NT Northern Territory, FNQ Far North Queensland ${ }^{1} N T$ Midwives' Data Collection, FNQ Queensland Health Case Mix reports

confidence in providing care, perceptions of care coordination and communication and how these have changed during the health systems intervention; perceived impact of the intervention on care for women whose pregnancies are complicated by hyperglycaemia; and sustainability of implementation activities.

Survey Healthcare providers in the study regions involved in the care or care coordination of women during and/or after a pregnancy complicated by hyperglycaemia will be invited through health professional networks to complete an online survey after completion of the implementation period. Participants will be asked about their usual practice in providing care for women during and after a pregnancy complicated by diabetes; confidence and support received in providing care; satisfaction with care pathways (e.g. access to specialist and allied health care) and communication between services; and awareness and engagement with activities of the health systems intervention. Response rates will be estimated by region and profession by comparing with number of professionals per region registered with relevant professional associations, where these numbers are available. Baseline survey data for comparison was previously collected during formative work [31,37].

Audit of Electronic Health Records and Diabetes in Pregnancy Clinical Register Primary care medical records and the DIP Clinical Register will be assessed using an independent sample, cross-sectional, pre- and post-intervention audit to determine the proportion of women receiving recommended care during and after pregnancy. In the NT, de-identified remote primary care medical records will be requested from NT Department of Health (DoH) for women with a birth due date in the final 12 months of implementation of the health systems intervention and who had a diagnosis of diabetes in pregnancy, and compared to baseline data already provided by NT DoH. In FNQ, data will be collected from the FNQ DIP Clinical Register, with baseline data including women giving birth in the first 12 months of the DIP Clinical Register's inception and post-intervention data including women giving birth in the final 12 months of the intervention. Data from primary healthcare provider electronic health records at evaluation case study sites not covered by NT DoH records (Aboriginal Community-Controlled Health Services in NT, and all FNQ evaluation sites) will also be requested for women with hyperglycaemia in pregnancy giving birth within the above time periods. Independent variables collected will include: study region; age; ethnicity; and type of diabetes. Outcome variables will include: number and timing of clinic visits (antenatal and postpartum); completion of recommended glucose screening in early pregnancy for high risk women; mean first- and thirdtrimester HbA1c; first- and third-trimester smoking status; postpartum variables within 6 months of birth including completion of glucose screening (including 75 gram OGTT, fasting glucose, HbA1c, random glucose, any glucose measure), weight, body mass index, waist circumference, breastfeeding status, smoking status and contraception use (prescribed or discussed with health practitioner); and birth and neonatal outcomes (gestational age at delivery, mode of delivery, birth weight, 
large for gestational age, small for gestational age, macrosomia, neonatal obstetric trauma, neonatal hypoglycaemia requiring treatment, neonatal special care admission, 5-minute APGAR score less than 5, neonatal jaundice requiring treatment, neonatal respiratory distress).

Implementation Operational Documents The intervention Activity Log will be reviewed, in addition to minutes of stakeholder meetings (including the Clinical and Indigenous Reference Groups) and attendance sheets and feedback forms from educational events.

\section{Data Analysis}

Qualitative Analyses Qualitative analyses of interview transcripts and operational documents will employ a hybrid inductive-deductive method. The first round of coding will be an inductive analysis; the second round of coding will involve a deductive analysis utilising the prespecified evaluation indicators. Themes will be clustered by study region, enabling comparison and contrast between regions. NVivo (version 12) will be used to assist the analysis processes.

Quantitative Analyses Survey data will be compared with baseline data collected through a prior health professional survey across the study regions, conducted during formative work for this health systems intervention $[31,37]$. Descriptive statistics will be reported. Changes between baseline and post-intervention for categorical variables will be analysed by Pearson's Chi-squared test or Fisher's exact test.

Data on outcome variables collected from the audit of electronic healthcare records and the DIP Clinical Register will be compared between baseline and postintervention periods. Changes between pre- and postintervention in categorical variables will be analysed using Pearson's Chi-squared test; changes in continuous variables will be analysed using student's $t$-test. Multivariable analysis will be performed using logistic regression for categorical and linear regression for continuous variables to assess relationships with independent variables, including age, ethnicity, and diabetes type.

All quantitative analyses will be performed using STATA 15.0 (StataCorp, College Station, Texas). The threshold for statistical significance will be defined as $p<$ 0.05 on two-tailed testing.

\section{Discussion}

Our health systems intervention is the first to our knowledge which aims to improve care both during pregnancy and the postpartum period for women across the broad spectrum of hyperglycaemia in pregnancy, including
GDM, pre-existing type 2 diabetes and overt diabetes in pregnancy. As described above, published work to date has focussed largely on improving postpartum glucose screening specifically in women with GDM [22-25]; despite widespread recommendations regarding provision of multidisciplinary care during and after pregnancy for women with pre-existing diabetes, a substantial knowledge gap regarding the evaluation of models of care for women with pre-existing diabetes has been identified by others [47]. Our health systems intervention is unique as it aims to improve care for women with all forms of hyperglycaemia in pregnancy, both during and after pregnancy. In addition, this intervention focuses on healthcare providers delivering care to a population with a high burden of disease in a complex setting.

The development of this health systems intervention from formative work conducted with health professionals is a strength of the project. This intervention aims to translate the knowledge of barriers and opportunities identified in our formative findings into tangible health service improvements. Previous work of the Partnership in the NT includes improving systems of care during pregnancy and implementing the NT DIP Clinical Register [26, 27]. These endeavours have resulted in the development of strong relationships between clinicians, policymakers and researchers. The current health systems intervention is strengthened through being informed by the input of these many stakeholders. Stakeholder collaboration will continue throughout implementation, further strengthening this intervention.

The mixed-methods evaluation, utilising multiple data sources, is another strength of this health systems intervention, enabling triangulation of findings. Quantitative audit data will demonstrate whether the intervention impacts on indicators of care provided to women during and after pregnancy, and on birth outcomes. Previous research has demonstrated the accuracy of routinely collected data regarding chronic conditions in electronic health records in remote Aboriginal communities, making this a useful resource for evaluation [48], together with use of our established DIP Clinical Register to assess pre- and post-intervention birth outcomes. The qualitative data will provide insights about acceptability and long-term feasibility of activities of the health systems intervention which will be essential information, both for planning sustainability of successful activities in the local setting and enabling replication in other settings.

The inclusion of multiple study regions, with different health systems operating across the regions and associated variation in organisational structure, policies and processes, is a challenge in this study, and will likely necessitate alterations in implementation activities depending on study region. However, this is also a strength of 
this intervention, providing an opportunity to assess how contextual factors of each region impact on the implementation and outcomes of the intervention. Information regarding contextual factors and their impact will form part of the findings of interest from this study.

The broad range of implementation activities that comprise this health systems intervention presents an additional challenge with regards to evaluating the impacts of these activities. This challenge is addressed through the use of multiple data sources within a structured evaluation framework, namely RE-AIM, which facilitates an in-depth exploration of the relative contributions of activities and their implementation to any observed outcomes.

Exploring the perspectives of Aboriginal and Torres Strait Islander women is essential in ensuring that healthcare is delivered in a way that meets these women's needs and is culturally safe and appropriate. The Partnership's Indigenous Reference Group is an important mechanism for ensuring voices of Aboriginal and Torres Strait Islander women are represented in this study. Additional planned work of the Partnership will ensure consumer perspectives are considered, namely those of Aboriginal and Torres Strait Islander women with a pregnancy complicated by hyperglycaemia, and inform future initiatives including greater engagement with consumers as participants of the intervention.

In conclusion, the Diabetes Across the Lifecourse: Northern Australia Partnership's health systems intervention has the potential to improve care for women during and after a pregnancy complicated by hyperglycaemia and intervene as early as possible in the life course to improve the health of women and their children. This study is anticipated to lead to improvements in clinician knowledge and skills in the management of hyperglycaemia in pregnancy. More broadly, this study has significance for health systems policy and implementation, particularly in populations at high risk of hyperglycaemia in pregnancy and transmission of risk to the next generation, including Indigenous peoples worldwide.

\section{Supplementary information}

Supplementary information accompanies this paper at https://doi.org/10 1186/s12913-020-05680-x.

Additional file 1. Revised Standards for Quality Improvement Reporting Excellence (SQUIRE 2.0) September 15, 2015

Additional file 2. The TIDieR (Template for Intervention Description and Replication) Checklist*

\section{Abbreviations}

BMI: Body mass index; CA: Central Australia; DIP: Diabetes in pregnancy; EHR: Electronic health record; FNQ: Far North Queensland; GDM: Gestational diabetes; HbA1c: Glycated haemoglobin A1c; NT: Northern Territory; OGTT: 75 gram oral glucose tolerance test; PANDORA: Pregnancy and
Neonatal Diabetes Outcomes in Remote Australia study; T2DM: Type 2 diabetes; TE: Top End

\section{Acknowledgements}

The Diabetes Across the Lifecourse: Northern Australia Partnership is a collaboration between researchers, policy makers and health organisations committed to using a lifecourse approach to improve care for people across Northern Australia with diabetes, focussing on hyperglycaemia in pregnancy and youth diabetes. We gratefully acknowledge all Diabetes Across the Lifecourse: Northern Australia Partnership staff and participants including Vanya Webster, Sian Graham, Dianne Bell, Katarina Keeler, Chenoa Wapau, Martil Zachariah, Jennifer Barrett, Tara Dias, Kristina Vine, Bronwyn Davis, Bonnie White; Partnership investigators; the Partnership Indigenous reference group, NT clinical reference group and FNQ working group; and health professionals across the NT and FNQ from hospitals, primary healthcare and Aboriginal Community Controlled Health Organisations who have contributed to the Partnership activities. Investigators of the Diabetes Across the Lifecourse: Northern Australia Partnership in addition to those named authors are: Chitturi S, Eades S, Inglis C, Dempsey K, Lynch M, Skinner T, Wright R. We appreciate the assistance of D Barnes in the preparation of Figure 1. Further information about the Diabetes Across the Lifecourse: Northern Australia Partnership can be obtained by contacting ntdippartnership@menzies.edu.au or dippinq@menzies.edu.au.

\section{Authors' contributions}

DM: final evaluation design; primary author of manuscript. RK: study design; data collection and interpretation of formative work; manuscript preparation. NF: evaluation design; manuscript preparation. KM, PVD: study design and implementation; manuscript preparation. JB, SCa, FB, CC, KO'D, JO, PZ, MW, AS, JS, AH, EM, DP, AM, BD, CW, HDM, JM, RM, SCO, KC, AB: study design and manuscript review for critical intellectual input. $L M B$ leads all aspects of this study including study concept and design; obtaining funding and ethics approval; supervision of data collection and implementation; and manuscript supervision and revision for critical intellectual input. All authors have read and approved the manuscript.

\section{Funding}

This study is funded by the Australian National Health and Medical Research Council (NHMRC) Global Alliance for Chronic Diseases Grant 1092968, and was independently peer-reviewed by this funding body. DM is supported by NHMRC Postgraduate Scholarship GNT1168668; JB was supported by NHMRC Career Development Fellowship; DP is supported by an NHMRC Career Development Fellowship (ID 1143904) and a Heart Foundation Future Leader Fellowship; JES was supported by NHMRC Fellowship 1079438; AB was supported by a Sylvia and Charles Viertel Senior Medical Research Fellowship and NHMRC Research Fellowship 1137563; LMB is supported by NHMRC Fellowship 605837. The views expressed in this publication are those of the authors and do not reflect the views of the NHMRC or Global Alliance for Chronic Diseases. The funders had no role in the study design, decision to publish or preparation of the manuscript.

Availability of data and materials Not applicable

Ethics approval and consent to participate

This study is approved by the Far North Queensland Human Research Ethics Committee (Cairns and Hinterland Hospital and Health Service, EC00157; approval HREC/16/QCH/15-1029), the Central Australian Human Research Ethics Committee (Northern Territory Government - Department of Health, EC00155; approval HREC-15-345) and the Human Research Ethics Committee of the Northern Territory Department of Health and Menzies School of Health Research (Northern Territory Government - Department of Health, EC00153; approval HREC-2015-2461).

Health professionals and key stakeholders in the NT who are approached to be involved in the research will receive a copy of a Plain Language Statement (PLS) and informed written consent will be sought. 


\section{Competing interests}

The authors declare that they have no competing interests.

\section{Author details}

${ }^{1}$ Menzies School of Health Research, Charles Darwin University, Darwin, Australia. ${ }^{2}$ Royal Darwin Hospital, Darwin, Australia. ${ }^{3}$ Baker Heart \& Diabetes Institute Central Australia, Alice Springs, Australia. ${ }^{4}$ Monash Centre for Health Research and Implementation, School of Public Health and Preventive Medicine, Monash University, Melbourne, Australia. ${ }^{5}$ College of Nursing and Midwifery, Charles Darwin University, Cairns, Australia. ${ }^{6}$ Top End Health Service, Northern Territory Department of Health, Darwin, Australia. ${ }^{7}$ Population School of Health Research, University of South Australia, Adelaide, Australia. ${ }^{8}$ Melbourne School of Population and Global Health, University of Melbourne, Melbourne, Australia. ${ }^{9}$ Department of Diabetes, Central Clinical School, Monash University, Melbourne, Australia. ${ }^{10}$ Apunipima Cape York Health Council, Bungalow, Australia. ${ }^{11}$ Cairns and Hinterland Hospital and Health Service, Cairns, Australia. ${ }^{2}$ Department of Nutritional Sciences, Faculty of Medicine and the Dalla Lana School of Public Health, The University of Toronto, Toronto, Canada. ${ }^{13}$ Aboriginal Medical Services Alliance Northern Territory, Darwin, Australia. ${ }^{14}$ The George Institute for Global Health, Sydney, Australia. ${ }^{15}$ Mater Medical Research Institute, University of Queensland, Brisbane, Australia. ${ }^{16}$ Wuchopperen Health Service, Cairns, Australia. ${ }^{17}$ Centre for Chronic Disease Prevention, Australian Institute of Tropical Health and Medicine, James Cook University, Cairns, Australia. ${ }^{18}$ Danila Dilba Health Service, Darwin, Australia. ${ }^{19}$ South Australian Health and Medical Research Institute, Adelaide, Australia. ${ }^{20}$ Aboriginal Health Domain, Baker IDI Heart and Diabetes Institute, Melbourne, Australia. ${ }^{21}$ Faculty of Health and Medical Science, University of Adelaide, Adelaide, Australia.

\section{Received: 30 July 2020 Accepted: 21 August 2020}

\section{Published online: 01 September 2020}

\section{References}

1. The HAPO Study Cooperative Research Group. Hyperglycemia and adverse pregnancy outcomes. New Engl J Med. 2008;358(19):1991-2002.

2. Dabelea D, Knowler WC, Pettitt DJ. Effect of diabetes in pregnancy on offspring: Follow-up research in the Pima indians. J Matern-Fetal Med. 2000; 9(1):83-8.

3. McIntyre D, Desoye G, Dunne F, Simeoni U, Visser GHA, Kapur A, et al. FIGO analysis of research priorities in hyperglycemia in pregnancy. Diab Res Clin Pract. 2018:145:5-14.

4. American Diabetes Association. 14 Management of diabetes in pregnancy: Standards Medical care in diabetes-2019. Diab Care. 2019; 42(Suppl 1):S165-S72.

5. Australasian Diabetes in Pregnancy Society. Position Statement - The Australasian Diabetes in Pregnancy Society consensus guidelines for the management of patients with type 1 and type 2 diabetes in relation to pregnancy: Australian Diabetes in Pregnancy Society; 2005 [Available from: https://www.adips.org/downloads/adips_pregdm_guidelines.pdf].

6. Carson MP, Frank MI, Keely E. Postpartum testing rates among women with a history of gestational diabetes_-Systematic review. Prim Care Diab. 2013; 7(3):177-86

7. Guariguata L, Whiting DR, Hambleton I, Beagley J, Linnenkamp U, Shaw JE. Global estimates of diabetes prevalence for 2013 and projections for 2035. Diab Res Clin Pract. 2014;103(2):137-49.

8. Porter C, Skinner T, Ellis I. The current state of Indigenous and Aboriginal women with diabetes in pregnancy: A systematic review. Diab Res Clin Pract. 2012;98:209-25.

9. Chamberlain C, McNamara B, Williams ED, Yore D, Oldenburg B, Oats J, et al. Diabetes in pregnancy among indigenous women in Australia, Canada, New Zealand and the United States. Diab Metab Res Rev. 2013;29(4):241-56.

10. Australian Institute of Health and Welfare. Diabetes in pregnancy: Its impact on Australian women and their babies. Canberra: AlHW; 2010.

11. Li L, O'Neil L. Mothers and Babies 2015: Northern Territory Midwives' Collection. Department of Health: Darwin; 2018.

12. Damm P, Houshmand-Oeregaard A, Kelstrup L, Lauenborg J, Mathiesen ER, Clausen TD. Gestational diabetes mellitus and long-term consequences for mother and offspring: a view from Denmark. Diabetologia. 2016;59(7):1396-9.

13. Chamberlain CR, Oldenburg B, Wilson AN, Eades SJ, O'Dea K, Oats JJN, et al. Type 2 diabetes after gestational diabetes: Greater than fourfold risk among
Indigenous compared with non-Indigenous Australian women. Diab Metab Res Rev. 2016:32:217-27.

14. Dabelea D. The predisposition to obesity and diabetes in offspring of diabetic mothers. Diab Care. 2007;30(Supplement 2):S169-S74.

15. Titmuss A, Davis EA, Brown A, Maple-Brown LJ. Emerging diabetes and metabolic conditions among Aboriginal and Torres Strait Islander young people. Med J Aust. 2019;210(3):111-3 e1.

16. Australian Institute of Health and Welfare. Australian Burden of Disease Study: Impact and causes of illness and death in Aboriginal and Torres Strait Islander people 2011. Canberra: AlHW; 2016. Contract No.: 6.

17. Australian Institute of Health and Welfare. Trends in Indigenous mortality and life expectancy, 2001-2015: Evidence from the Enhanced Mortality Database. Canberra: AlHW; 2017. Contract No.: IHW 174.

18. Stasenko M, Liddell J, Cheng YW, Sparks TN, Killion M, Caughey AB. Patient counseling increases postpartum follow-up in women with gestational diabetes mellitus. Am J Obstet Gynecol. 2011;204(6):522 e1-e6.

19. Lega IC, McLaughlin H, Coroneos M, Handley-Derry F, Donovan N, Lipscombe LL. A physician reminder to improve postpartum diabetes screening in women with gestational diabetes mellitus. Diab Res Clin Pract. 2012;95(3):352-7.

20. Jeppesen C, Kristensen JK, Ovesen P, Maindal HT. The forgotten risk? A systematic review of the effect of reminder systems for postpartum screening for type 2 diabetes in women with previous gestational diabetes. BMC Res Notes. 2015;8(1):373.

21. Yarrington $C$, Zera $C$. Health systems approaches to diabetes screening and prevention in women with a history of gestational diabetes. Curr Diab Rep. 2015:15(12):114.

22. Dietz PM, Vesco KK, Callaghan WM, Bachman DJ, Bruce FC, Berg CJ, et al. Postpartum screening for diabetes after a gestational diabetes mellitusaffected pregnancy. Obstet Gynecol. 2008;112(4):868-74.

23. Vesco KK, Dietz PM, Bulkley J, Bruce FC, Callaghan WM, England L, et al. A system-based intervention to improve postpartum diabetes screening among women with gestational diabetes. Am J Obstet Gynecol. 2012 207(4):283 e1-e6.

24. O'Reilly SL, Dunbar JA, Best JD, Versace V, Ford D, Young D, et al. GooD4Mum: A general practice-based quality improvement collaborative for diabetes prevention in women with previous gestational diabetes. Prim Care Diab. 2019;13(2):134-41.

25. Bhavadharini B, Anjana RM, Mahalakshmi MM, Maheswari K, Kayal A, Unnikrishnan R, et al. Glucose tolerance status of Asian Indian women with gestational diabetes at 6 weeks to 1 year postpartum (WINGS-7). Diab Res Clin Pract. 2016;117:22-7.

26. Kirkham R, Boyle JA, Whitbread C, Dowden M, Connors C, Corpus S, et al. Health service changes to address diabetes in pregnancy in a complex setting: Perspectives of health professionals. BMC Health Serv Res. 2017;17:524.

27. Kirkham R, Whitbread C, Connors C, Moore E, Boyle JA, Richa R, et al. Implementation of a diabetes in pregnancy clinical register in a complex setting: Findings from a process evaluation. PloS One. 2017;12(8):e0179487.

28. Katzenellenbogen JM, Ralph AP, Wyber R, Carapetis JR. Rheumatic heart disease: infectious disease origin, chronic care approach. BMC Health Serv Res. 2017;17(1):793.

29. McDermott RA, McCulloch BG, Campbell SK, Young DM. Diabetes in the Torres Strait Islands of Australia: better clinical systems but significant increase in weight and other risk conditions among adults, 1999-2005. Med J Australia; 2007;186(10):505-8.

30. Edwards L, Connors C, Whitbread C, Brown A, Oats J, Maple-Brown L. Improving health service delivery for women with diabetes in pregnancy in remote Australia: Survey of care in the Northern Territory Diabetes in Pregnancy Partnership. Aust New Zealand J Obstet Gynaecol. 2014;54(6): 534-40.

31. McLean A, Kirkham R, Campbell S, Whitbread C, Barrett J, Connors C, et al. Improving models of care for diabetes in pregnancy: Experience of current practice in Far North Queensland, Australia. Front Public Health. 2019;7(192).

32. Hoffmann TC, Glasziou PP, Boutron I, Milne R, Perera R, Moher D, et al. Better reporting of interventions: Template for intervention description and replication (TIDieR) checklist and guide. Br Med J. 2014:348.

33. Ogrinc G, Davies L, Goodman D, Batalden P, Davidoff F, Stevens D. SQUIRE 2.0 (Standards for QUality Improvement Reporting Excellence): Revised publication guidelines from a detailed consensus process. BMJ Qual Saf. 2016;25(12):986-92. 
34. French SD, Green SE, O'Connor DA, McKenzie JE, Francis JJ, Michie S, et al. Developing theory-informed behaviour change interventions to implement evidence into practice: a systematic approach using the Theoretical Domains Framework. Implement Sci. 2012;7(1):38.

35. Central Australian Rural Practitioners Association Inc. Minymaku Kutju Tjukurpa - Women's Business Manual. 6th. ed. Alice Springs: RPHCM; 2017.

36. Queensland Clinical Guidelines. Gestational diabetes mellitus. Department of Health; 2015.

37. Kirkham R, Trap-Jensen N, BJ A, Barzi F, Barr E, Whitbread C, et al. Diabetes care in remote Australia: The antenatal, postpartum and inter-pregnancy period. BMC Pregnancy Child. 2019;19:389

38. Cairns and Hinterland Hospital and Health Service. Annual Report 20172018. Queensland Government; 2018.

39. Torres and Cape Hospital and Health Service. Annual Report 2017-2018. Queensland Government; 2018.

40. Department of Health - Strategy Policy and Planning Branch. Northern Territory Health Strategic Plan 2018-2022. Northern Territory Government; 2018.

41. Australian Bureau of Statistics. 3101.0 Australian Demographic Statistics (Sep 2018). ABS; 2019 Mar 21

42. Davis B, McLean A, Sinha AK, Falhammar H. A threefold increase in gestational diabetes over two years: Review of screening practices and pregnancy outcomes in Indigenous women of Cape York, Australia. Aust New Zealand J Obstet Gynaecol. 2013;53(4):363-8.

43. Maple-Brown $L$, Lindenmayer G, Barzi F, Whitbread C, Connors C, Moore E, et al. Real-world experience of metformin use in pregnancy: Observational data from the Northern Territory Diabetes in Pregnancy Clinical Register. Journal of Diabetes. 2019.

44. Glasgow RE, Vogt TM, Boles SM. Evaluating the public health impact of health promotion interventions: The RE-AIM framework. Am J Public Health. 1999:89(9):1322-7.

45. Holtrop JS, Rabin BA, Glasgow RE. Qualitative approaches to use of the RE-AIM framework: Rationale and methods. BMC Health Serv Res. 2018;18(1):177.

46. Glasgow RE, Harden SM, Gaglio B, Rabin B, Smith ML, Porter GC, et al. REAIM planning and evaluation framework: Adapting to new science and practice with a 20-year review. Front Public Health. 2019;7(64).

47. Bick D, Beake S, Chappell L, Ismail KM, McCance DR, Green JSA, et al. Management of pregnant and postnatal women with pre-existing diabetes or cardiac disease using multi-disciplinary team models of care: A systematic review. BMC Pregnancy Child. 2014;14:428.

48. Davis S, Reeve C, Humphreys JS. How good are routinely collected primary healthcare data for evaluating the effectiveness of health service provision in a remote Aboriginal community? Rural Remote Health. 2015;15(4):1-9.

\section{Publisher's Note}

Springer Nature remains neutral with regard to jurisdictional claims in published maps and institutional affiliations.

Ready to submit your research? Choose BMC and benefit from:

- fast, convenient online submission

- thorough peer review by experienced researchers in your field

- rapid publication on acceptance

- support for research data, including large and complex data types

- gold Open Access which fosters wider collaboration and increased citations

- maximum visibility for your research: over $100 \mathrm{M}$ website views per year

At $\mathrm{BMC}$, research is always in progress.

Learn more biomedcentral.com/submissions 